\title{
Dental microwear as a diet indicator in the seventeenth-century human population from lasi City, Romania
}

\author{
Ozana-Maria Petraru ${ }^{1,2} \cdot$ Vasilica-Monica Groza $^{1} \cdot$ Andrei Lobiuc $^{3} \cdot$ Luminita Bejenaru $^{1,2}$ (I) $\cdot$ Mariana Popovici $^{1}$
}

Received: 1 January 2020 / Accepted: 10 July 2020 / Published online: 23 July 2020

(C) The Author(s) 2020

\begin{abstract}
The dental microwear analysis (DMA) focuses on diet reconstructions, being able to provide proxy indicators of some events regarding technological shifts in food processing and social hierarchy and differences between individuals. Although DMA approaches diet characterization in ancient times, medieval samples have received limited attention, especially in Eastern Europe. The aim of this article is to explore, identify, and describe within-group patterns of dental microwear variation depending on sex and anatomic position (i.e., left/right, superior/inferior). The bioarchaeological material belongs to the Princely Court Necropolis of the seventeenth century discovered in Iasi (Romania) - the former capital city of Medieval Moldavia. We analyzed the micromorphological features on the occlusal surface of the second molar tooth through scanning electronic microscopy and imaging. Quantification of the microwear features (i.e., fine and coarse scratches, small and large pits) along with their bidimensional measurements (i.e., length and width) has been subjected to multivariate analysis. Our results show heterogeneous distribution of the microwear features within the analyzed second molars. Although the general microwear profile is dominated by fine and coarse scratches, large pits are also present. We can generally characterize the food as abrasive and relatively hard. In females, there are two microwear profiles highlighted based on the molar laterality, which suggests the use of the right side of the oral cavity to process harder foods. In males, the microwear profile is homogeneous and does not differ by laterality; it shows a great affinity with the pattern of the female right molars.
\end{abstract}

Keywords Dental microwear $\cdot$ Sex $\cdot$ Laterality $\cdot$ Diet $\cdot$ Seventeenth century $\cdot$ Iasi (Romania)

\section{Introduction}

Dietary reconstruction is a fundamental niche in paleoanthropology, inasmuch as food can be a biomarker in human evolution, migrations, cultural behavior, and social organization, providing information regarding human paleobiology and paleoenvironment (Salazar-García et al. 2017; Ungar and Sponheimer 2011). Diet has been studied through stable isotopes, starch grain microfossils, phytoliths and pollen, and microbial DNA from dental calculus (Buckley et al. 2014;

Luminita Bejenaru

lumib@uaic.ro

1 Romanian Academy - Iaşi Branch, "Olga Necrasov" Center of Anthropological Research, Iasi, Romania

2 Faculty of Biology, "Alexandru Ioan Cuza" University of Iași, Iasi, Romania

3 Institute of Interdisciplinary Research - CERNESIM Centre, "Alexandru Ioan Cuza" University of Iași, Iasi, Romania
Cummings et al. 2018; Henry and Piperno 2008; Weyrich et al. 2017) and by microscopic methods for assessing dental macrowear (Górka et al. 2016; Petraru et al. 2018) and microwear (García-González et al. 2015; Mahoney 2006b; Schmidt 2010; Sołtysiak 2011).

Dental wear is the result of processes like abrasion (produced by the interaction between the teeth and other materials), attrition (produced by tooth-tooth contacts), and erosion (chemical wear produced by acidic agents) (Addy and Shellis 2006; Levrini et al. 2014). Another dental wear process is abfraction, which is associated with mastication, swallowing, and malocclusion forces; it manifests through microfractures and microstructural loss (Michael et al. 2009). Dental wear can be observed at both macroscopic (macrowear) and microscopic (microwear) scales.

The dental microwear analysis (DMA) has been used to characterize the diet of humans from the Paleolithic (Fiorenza et al. 2018; García-González et al. 2015; Mahoney 2006b), Neolithic, Bronze, Iron (Mahoney 2006a; Polo-Cerdá et al. 2007) to Middle Ages (Organ et al. 2005; Salazar-García et al. 2016; Smith et al. 2019). Studies concerning DMA can provide important 
indicators of past events regarding technological shifts in food processing, variation in diet, social hierarchy, and differences between individuals (García-González et al. 2019; Sołtysiak 2011). Dental microwear is visible under high power magnification and is caused by abrasive particles as they move upon the dental surface during chewing (Schmidt 2010). Known as the "Last Supper effect" (Grine 1986), dental microwear is due to a short-term process, reflecting the mechanical properties of the food and abrasives consumed in the weeks or even months before death (Scott and Halcrow 2017).

There are two main types of microwear features: linear features known as scratches and nonlinear features termed depressions or pits (Schmidt 2010; Smith et al. 2019). A pit is defined as having a length-to-width ratio of less than four-to-one, while a scratch has a length-to-width ratio that exceeds four-to-one (Schmidt 2010). Usually, soft food can create both fine scratches and small pits, but with a different frequency; leaves, meat, and gruels often cause parallel scratches on the dental surface (Organ et al. 2005; Ungar 2019). A more or less abrasive diet can be reflected by the ratio between linear and nonlinear marks and by their number and size (i.e., length and breadth) (Soltysiak 2011). Microwear profiles dominated by few fine scratches are associated with relatively soft food. An abrasive diet leaves greater and more pronounced marks such as wide scratches. Harder food items produce more pits due to both the hard nature of items and the effect of chewing forces during mastication. Pitting may be caused by items such as bone fragments, nut shells, hard parts of fruits and seeds, some invertebrate exoskeletons, and phytoliths (Mahoney 2006b; Smith et al. 2019; Xia et al. 2015). It is hard to identify which foods caused one particularly microwear pattern. However, it is known that some hard items are crushed causing pitting and others are sheared and produce scratches on the enamel surface (Ungar 2019). For instance, phytoliths can produce both pits and scratches.

Although the dental microwear analysis (DMA) focuses on diet reconstruction of early hominins, dietary transitions, and diachronic and synchronic evaluation of the paleo diet, it can also approach the food variation within groups. Medieval communities can also be approached from the perspective of dental wear, in order to evaluate the physical properties (abrasiveness, hardness) of the food ingested. Though most articles address DMA for dietary characterization, the knowledge of within-group food variation is still precarious (Pérez-Pérez et al. 1994; Smith et al. 2019). Likewise, in northeastern Romania, paleo diet and DMA studies are lacking, even though this region has a rich archeological heritage due to its strategic position in old Europe. The former capital city of Medieval Moldavia, Iasi City (Fig. 1), was marked by episodes of cultural and economic development interrupted by dramatic events such as numerous Tatar, Turkish, or Polish invasions (Cloșcă 2008).

In 2008, a necropolis of the seventeenth century was discovered in the eastern part of the former Princely Court in Iasi City $\left(47^{\circ} 09^{\prime} 23^{\prime \prime} \mathrm{N}, 27^{\circ} 35^{\prime} 14.8^{\prime \prime} \mathrm{E}\right.$, source: Google Earth). Today, remains of the former Princely Court (e.g. ruins, bastions, and cellars) are incorporated within the building named Palace of Culture (Badarau and Caproșu 2007). In this necropolis, 60 individual and collective tombs were discovered, from which 111 skeletons were recovered (Groza 2015). Some aspects of the archeological research are still unpublished, although the human skeletons have been extensively studied (Groza 2013, 2015; Groza et al. 2011). The anthropological studies highlighted some particularities of the necropolis: the absence of children; a disproportionate sex ratio ( 80 males/31 females); the males aged 35-60 years have a high frequency $(>50 \%)$; they are described by massiveness, robustness and typological polymorphism (Groza 2013; Popovici et al. 2019). A recent study, regarding the dental macrowear on the M2 molars showed differences by sex, probably mainly associated with greater consumption of abrasive and erosive food by males than by females (Petraru et al. 2018).

To confirm this assumption, we analyzed the micromorphological features on the M2 molar occlusal surfaces (microwear analysis) through scanning electronic microscopy and imaging. The aim of this article is to identify the withingroup patterns of dental microwear variation, depending on sex and tooth anatomic position (i.e., left/right, upper/lower). Based on previous research, we assume that men have a different dental microwear profile than women, which may have social significance in terms of food access.

There are some limitations to this study that concern with methodological aspects. We applied the SEM methodology to observe and analyze the enamel marks in two-dimensional images, but in order to reduce the errors of measurements, we used three consecutive nonoverlapping micrographs/molar in a semiautomated software. The SEM analysis was destructive for archeological samples, but it was limited only on a single type of tooth (M2); the other teeth have remained intact and can be used for further analysis. The dental microwear evaluation is restricted at the occlusal surface, only on a specific area (facet 9), according to the methodology indicated by some researchers and due to the availability of the anthropological material. In the current stage of our research, we focused only on the study of dental wear. We will be able to correlate these results with the data of new analyses (e.g. stable isotopes, microbiome DNA profiling), which will be possible in collaboration with other specialized laboratories.

\section{Material and methods}

\section{Material}

This study is based on the analysis of left and right, maxillary (superior) and mandibular (inferior) second molars (M2), which belong to the skeletons discovered in the seventeenthcentury necropolis from Iasi (Romania). The M2 molars ( $n=$ 


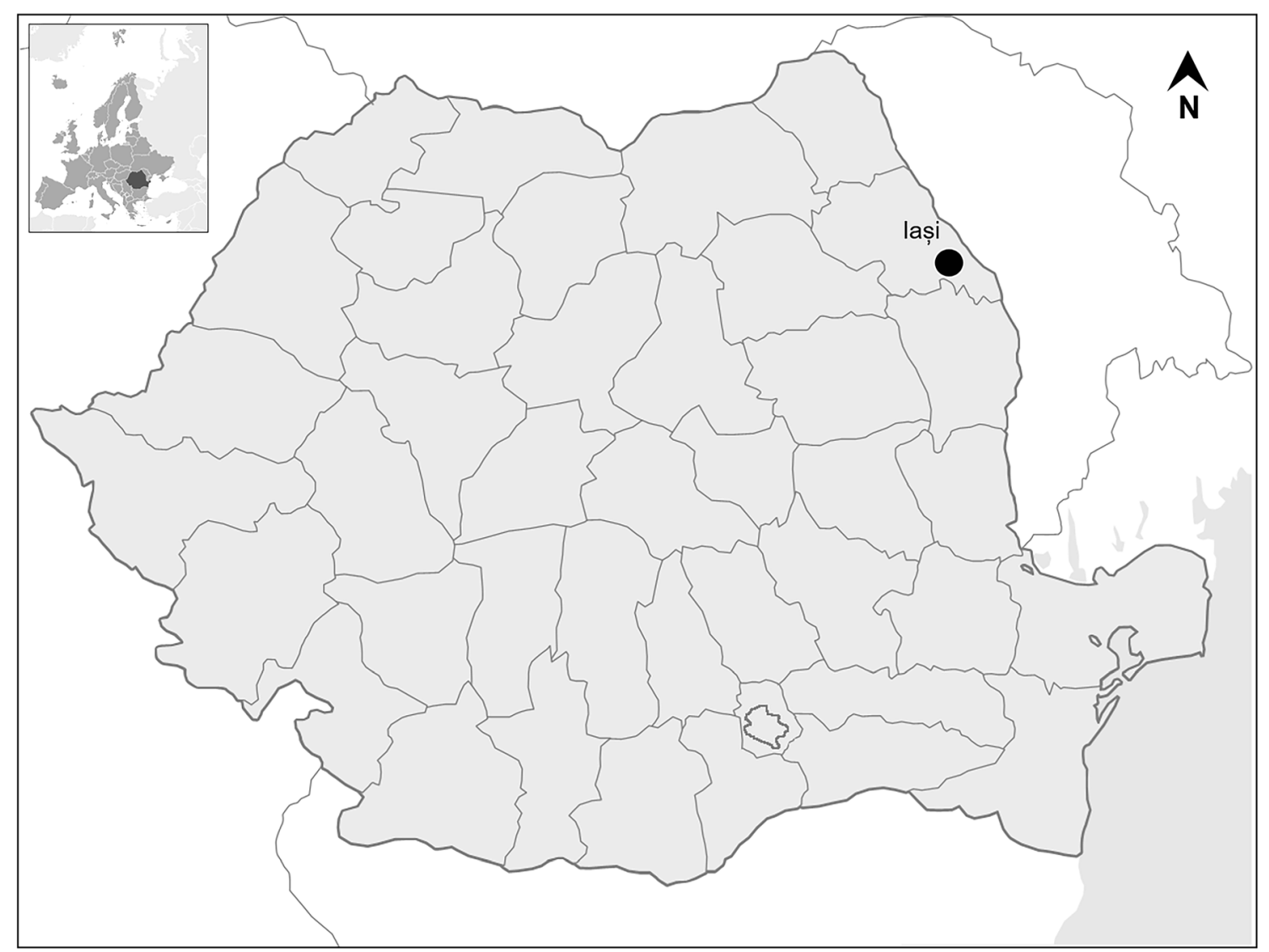

Fig. 1 Location of the Iasi City, Romania

56) were selected, while the first and third molars were avoided because M1 has a variable morphology and a high degree of wear and M3 is not always present - congenitally missing. The selected samples belong to skeletons with differing ages at death and sex previously estimated by Groza et al. (2011) (Table 1).

\section{Methods}

\section{Imaging}

The dental microwear analysis (DMA) was performed on facet 9 (Fig. 2) of the distobuccal cusp (mandibular molars) and mesiolingual cusp (maxillary molars) (Fiorenza et al. 2011; García-González et al. 2015; Mahoney 2006b), using a scanning electron microscope (SEM) Tescan Vega II SBH. Contaminants were removed from the dental surface using ethanol and cotton wool (Mahoney 2006a). Each sample was mounted on an aluminum stub and placed into a Sputter Coating Unit EMS 550X to receive a $30 \mathrm{~nm}$ layer of gold. The occlusal surface which corresponds to the facet 9 area was imaged through three consecutive nonoverlapping micrographs/molar, toward the bottom, middle, and tip of the facet.

\section{Microwear analysis}

Micrographs were analyzed through an early version of MicroWear software (Strani et al. 2018). On each micrograph, on an area of $0.3025 \mathrm{~mm}^{2}$, microwear features were identified and automatically classified on the length/width ratio (4:1) (Strani et al. 2018; Ungar 1995), as linear marks (fine scratches and coarse scratches) and nonlinear marks (small pits and large pits). Variables such as the number of pits, small pits, large pits, scratches, fine scratches, and coarse scratches, along with data concerning the mean and standard deviation of lengths and widths of identified features, were automatically obtained. The presence of scratches that cross each other and a number of parallel scratches were also reported (Strani et al. 2019).

\section{Statistical analysis}

For this study, the following variables were used: width and length of small pits ( $\mathrm{sp}-\mathrm{w}, \mathrm{sp}-\mathrm{l}$ ), width and length of large pits (lp-w, lp-l), width and length of fine scratches (fs-w, fs-l), and the width and length of coarse scratches (cs-w, cs-l). Even if the scratch length variables (fs-l and cs-1) are the most disputable due to the possibility of being truncated by the edge of the 
Table 1 Age at death and sex profile of the selected molar teeth

\begin{tabular}{lllll}
\hline No. & Skeleton code & Age group & Sex & Molars \\
\hline 1 & $\mathrm{M}_{\mathrm{XVI}}$ & Adolescent (12-20 years) & Female & $\mathrm{M}^{21}, \mathrm{M}^{2 \mathrm{r}}, \mathrm{m}_{21}, \mathrm{~m}_{2 \mathrm{r}}$ \\
2 & $\mathrm{G}_{2} \mathrm{M}_{6}$ & & Male & $\mathrm{M}^{21}, \mathrm{M}^{2 \mathrm{r}}, \mathrm{m}_{21}, \mathrm{~m}_{2 \mathrm{r}}$ \\
3 & $\mathrm{G}_{3} \mathrm{M}_{9}$ & Young adults (20-34 years) & Female & $\mathrm{M}^{21}, \mathrm{M}^{2 \mathrm{r}}, \mathrm{m}_{21}, \mathrm{~m}_{2 \mathrm{r}}$ \\
4 & $\mathrm{G}_{5} \mathrm{M}_{16}$ & & Female & $\mathrm{M}^{21}, \mathrm{M}^{2 \mathrm{r}}, \mathrm{m}_{21}, \mathrm{~m}_{2 \mathrm{r}}$ \\
5 & $\mathrm{G}_{14} \mathrm{M}_{47}$ & & Male & $\mathrm{M}^{21}, \mathrm{M}^{2 \mathrm{r}}, \mathrm{m}_{21}, \mathrm{~m}_{2 \mathrm{r}}$ \\
6 & $\mathrm{G}_{13} \mathrm{M}_{41}$ & & Male & $\mathrm{M}^{21}, \mathrm{M}^{2 \mathrm{r}}, \mathrm{m}_{21}, \mathrm{~m}_{2 \mathrm{r}}$ \\
7 & $\mathrm{M}_{1}$ & Middle adults & Male & $\mathrm{M}^{21}, \mathrm{M}^{2 \mathrm{r}}, \mathrm{m}_{21}, \mathrm{~m}_{2 \mathrm{r}}$ \\
8 & $\mathrm{G}_{9} \mathrm{M}_{27}$ & (35-49 years) & Male & $\mathrm{M}^{21}, \mathrm{M}^{2 \mathrm{r}}, \mathrm{m}_{21}, \mathrm{~m}_{2 \mathrm{r}}$ \\
9 & $\mathrm{M}_{29}$ & & Male & $\mathrm{M}^{21}, \mathrm{M}^{2 \mathrm{r}}, \mathrm{m}_{21}, \mathrm{~m}_{2 \mathrm{r}}$ \\
10 & $\mathrm{G}_{14} \mathrm{M}_{14}$ & & Female & $\mathrm{M}^{21}, \mathrm{M}^{2 \mathrm{r}}, \mathrm{m}_{21}, \mathrm{~m}_{2 \mathrm{r}}, \mathrm{M}^{2 \mathrm{r}}, \mathrm{m}_{21}, \mathrm{~m}_{2 \mathrm{r}}$ \\
11 & $\mathrm{G}_{4} \mathrm{M}_{15}$ & & Male & $\mathrm{M}^{21}, \mathrm{M}^{2 \mathrm{r}}, \mathrm{m}_{21}, \mathrm{~m}_{2 \mathrm{r}}$ \\
12 & $\mathrm{G}_{14} \mathrm{M}_{44}$ & & Female & $\mathrm{M}^{21}, \mathrm{M}^{2 \mathrm{r}}, \mathrm{m}_{21}, \mathrm{~m}_{2 \mathrm{r}}$ \\
13 & $\mathrm{M}_{\mathrm{V}}$ & & Male & $\mathrm{M}^{21}, \mathrm{M}^{2 \mathrm{r}}, \mathrm{m}_{21}, \mathrm{~m}_{2 \mathrm{r}}$ \\
14 & $\mathrm{G}_{19} \mathrm{M}_{65}$ & Old adults (50+ years) & &
\end{tabular}

$* M^{2 l}$ left superior second molar, $M^{2 r}$ right superior second molar, $m_{2 l}$ left inferior second molar, $m_{2 r}$ right inferior second molar

micrograph, we consider these variables in order to obtain as much information as possible (Schmidt 2010).

The Shapiro-Wilk test for assessing normality of variables and Q-Q plots were initially used (Razali and Wah 2011). Metric variables were evaluated separately for each sex and anatomic position (right and left sides). A $t$ test was performed to determine if there were any differences between maxillary and mandibular molar microwear patterns. The MannWhitney $\mathrm{U}$ test is a nonparametric version of the $t$ test and was used to examine statistical differences between variables with a non-normal distribution. The paired sample $t$ test was used to determine if there were differences between left and right molar microwear patterns. This test assumes that the differences calculated for each pair have an approximately normal distribution. The Wilcoxon test is the nonparametric version of the paired sample $t$ test and was used to examine the distribution of variables whose data are not normally distributed.
The principal component analysis (PCA) was used as an exploratory tool for data reduction and correlation of the variables underlying microwear patterns and relationships between molars. The variation patterns for both sexes were analyzed with multivariate analysis of variance (MANOVA) and canonical variate analysis (CVA). Also, discriminant analyses (DA) were performed to examine the patterns of molar variations. Plots and all statistical tests were conducted using XLSTAT Premium version 2019.2.1, PAST (Hammer et al. 2001) and R software (R Core Team 2013).

\section{Results and discussion}

All four types of microwear are unequally distributed in the analyzed M2 molars. In the female series (except for the G4M14 skeleton), our results show the distribution of fine scratches more on the $\mathrm{M}^{21}$ and $\mathrm{m}_{21}$ and then on the $\mathrm{M}^{2 \mathrm{r}}$ and
Fig. 2 Location of facet 9 (rectangular area) on the left mandibular (A) and maxillary (B) molars
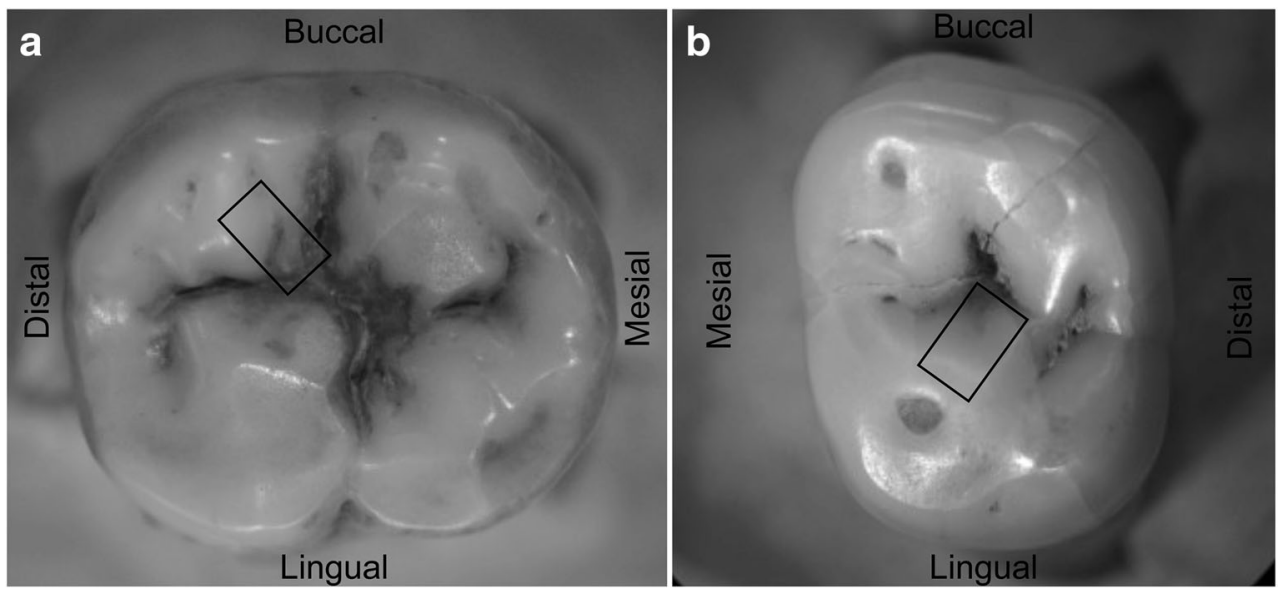
Fig. 3 Distribution of dental microwear features in males (A) and females (B); N.fs, number of fine scratches; N.cs, number of coarse scratches; N.lp, number of large pits; N.sp, number of small pits a

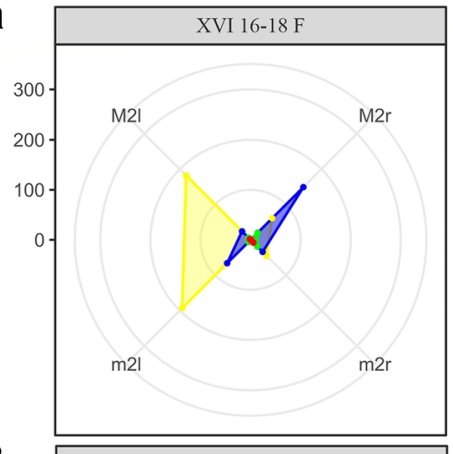

$\stackrel{\circ}{2}$

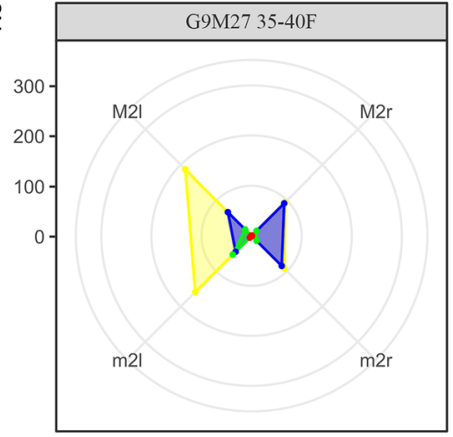

b
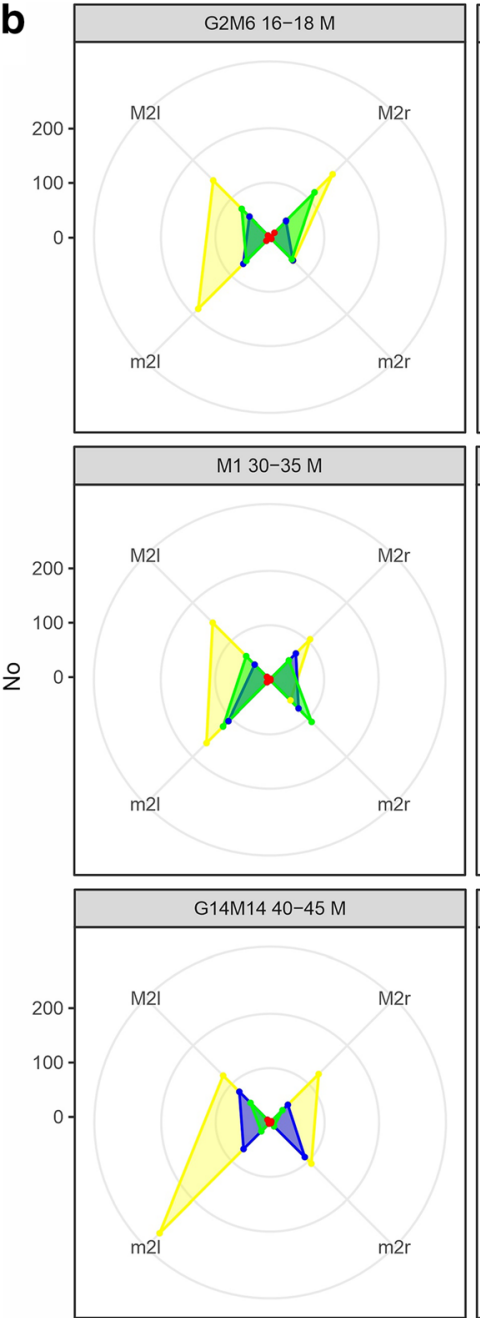
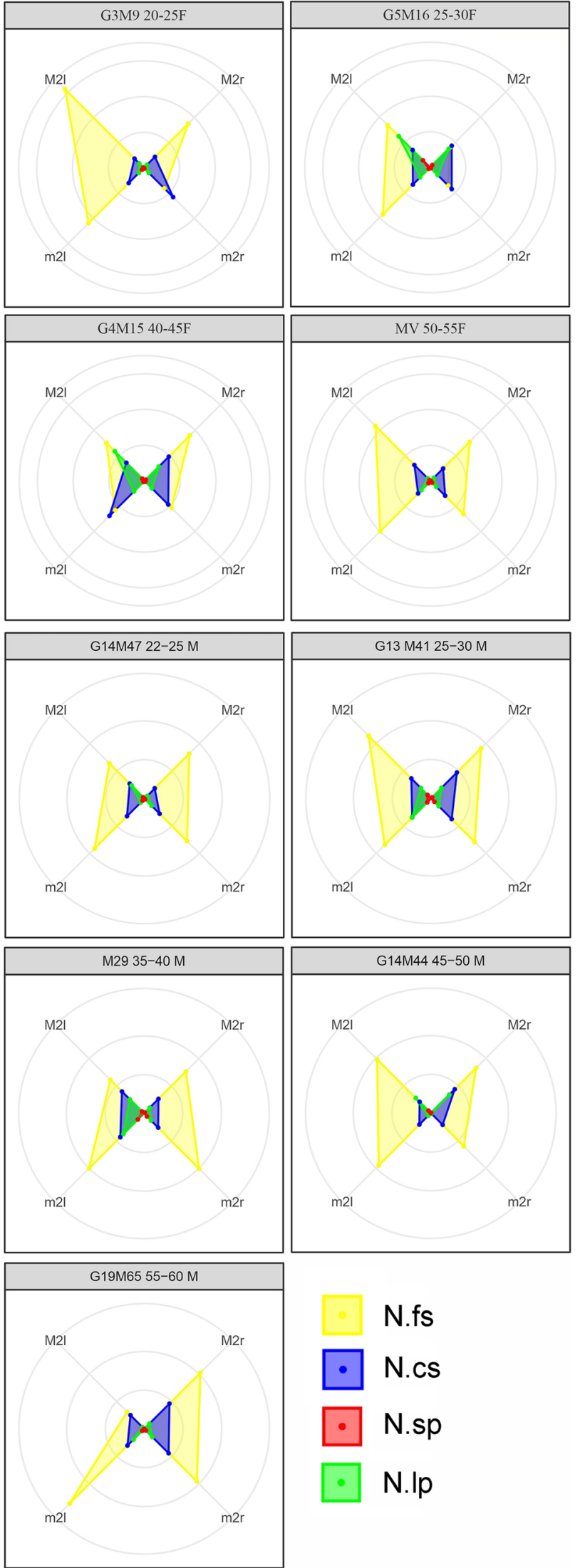

N.fs

N.cs

- N.sp

- N.Ip 
Fig. 4 Group centroids in discriminant analysis $\left(\mathrm{M}^{21}\right.$, left superior second molar; $\mathrm{M}^{2 \mathrm{r}}$, right superior second molar; $\mathrm{m}_{21}$, left inferior second molar; $\mathrm{m}_{2 \mathrm{r}}$, right inferior second molar)

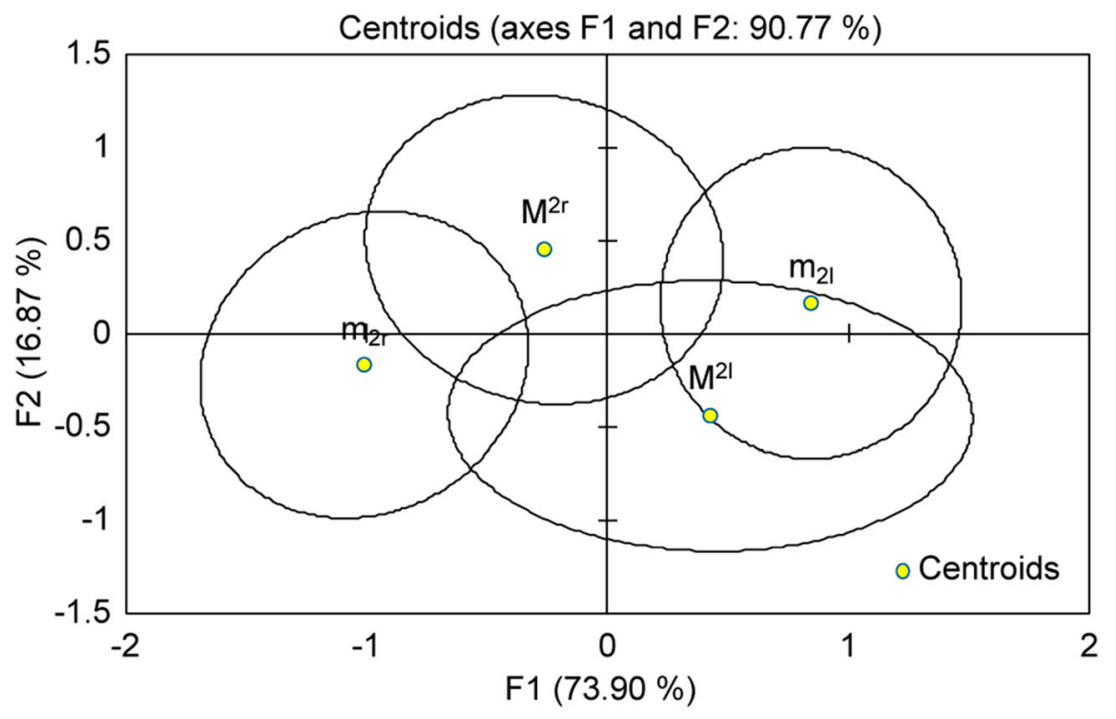

$\mathrm{m}_{2 \mathrm{r}}$. The numeric distribution of microwear features for each individual is shown in Fig. 3.

The microwear data obtained by micrograph analysis have been subjected to DA. The four quantitative variables (N.fs, N.cs, N.lp, N.sp) and two qualitative variables (sex and molar position in skull) were used. The molars are represented on the first two factor axes through centroid groups (Fig. 4). The teeth were reclassified into two main patterns. The results provided a discrimination with $53.7 \%$ of extant patterns (mean value), with the highest discrimination for the molars of left and right sides $(64.29 \%$ correct classification). The first factor F1 is characterized by $73.89 \%$ of the variance and is correlated with the N.fs variable. This discrimination between two patterns is due to the number of fine scratches: more on the surface on $\mathrm{m}_{21}$ and less on $\mathrm{m}_{2 \mathrm{r}}$. These patterns are present especially in females. To a lesser extent, F2 is correlated with N.cs and N.sp (16.87\%).

The right mandibular microwear profile is characterized by a lower number of fine scratches than the left mandibular profile. Also, the mean of scratches is higher on $\mathrm{m}_{21}$ (mean $=$

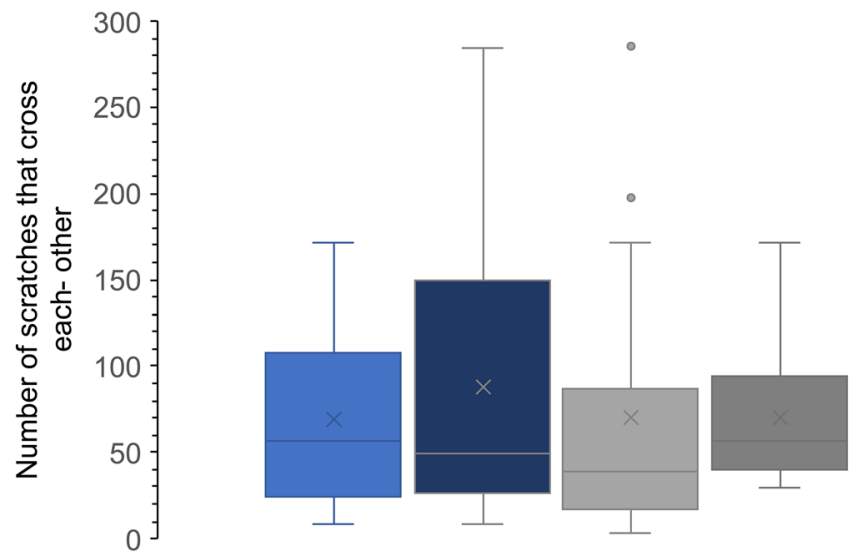

a $\square$ females - rs $\square$ females - Is $\square$ males - rs $\square$ males - Is Fig. 5 Boxplots showing numbers of pairs of parallel (A) and crossed (B) scratches represented on sex and laterality criteria; *statistically significant, $p<0.05$
196.4) than on $\mathrm{m}_{2 \mathrm{r}}($ mean $=117.2)$. The coefficient of variation value $(\mathrm{CV} \%)$ varies from 41.57 for the $\mathrm{m}_{2 \mathrm{r}}$ pattern, to 22.67 for the $\mathrm{m}_{21}$ pattern. The microwear pattern that characterizes the right mandibular molars differs from the left one in the number of large pits (mean value of N.lp $=24.15$ for the $\mathrm{m}_{2 \mathrm{r}}$ pattern and 41.46 for $\left.\mathrm{m}_{21}\right)$. Regarding the other two variables (N.sp and N.cs), similar values were observed for the two microwear patterns (mean N.sp $=4.61$ for $\mathrm{m}_{2 \mathrm{r}}$ and 6.46 for $\mathrm{m}_{21}$, while mean N. cs $=72.07$ for $\mathrm{m}_{2 \mathrm{r}}$ and 71.15 for $\mathrm{m}_{21}$ ).

The orientation of the scratches also suggests a difference in the microwear pattern between the right and left molars (Fig. 5). The number of pairs of parallel scratches is higher in females on the $\mathrm{M}^{21}$ and $\mathrm{m}_{21}$ molars than on $\mathrm{M}^{2 \mathrm{r}}$ and $\mathrm{m}_{2 \mathrm{r}}$ $(* p<0.05)$. No statistical significance is apparent in the male dataset for the number of crossed and parallel scratches.

The microwear types were quantified for $56 \mathrm{M}$ with three micrographs for each tooth, summing to an analyzed surface area of $0.9075 \mathrm{~mm}^{2} / \mathrm{M}$. When assigned by sex criteria, there were no differences between the percentage of fine scratches and large and small pits. The average percentages of the

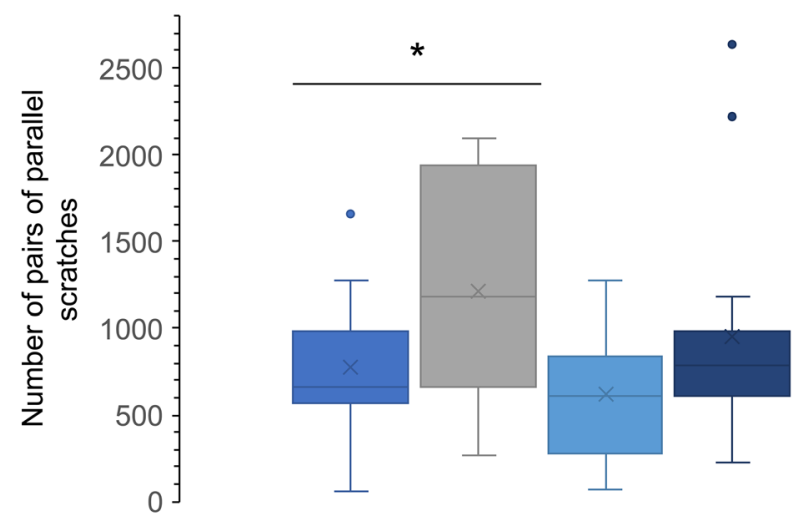
b $\square$ females - rs $\square$ females - Is $\square$ males - rs $\square$ males - Is
es represented on sex and laterality criteria; *statistically significant, $p<0.05$ 
Fig. 6 Average percentage of microwear features (sm, small pits; lp, large pits; fs, fine scratches; cs, coarse scratches; f, females; m, males; *statistically significant, $p<0.05$ )

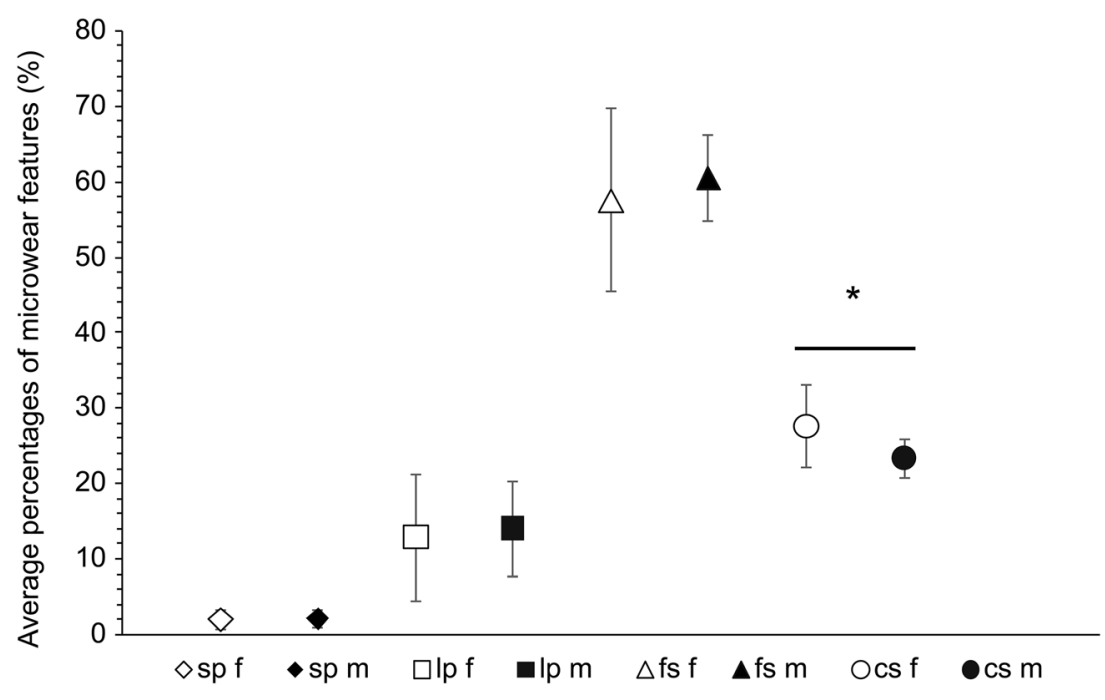

microwear features are presented in Fig. 6. A significant statistical difference was observed in the frequency of coarse scratches between the female and male datasets $(p=0.49)$. When sex was pooled, the total microwear profile was dominated by fine scratches $(57.88 \%)$, followed by coarse scratches $(25.60 \%)$. Lower values were registered for nonlinear marks: $1.93 \%$ for small pits and $14.57 \%$ for large pits.

Based on the number of recorded microwear features, an attempt to define a characteristic diet is difficult. It is well known that all diets can produce some form of marks including pitting (Mahoney 2006b). Our results show that the general microwear profile is dominated by linear marks. Even if the abundance of fine scratches is higher, the number of wider scratches and large pits is also remarkable due to their similar values. According to Sołtysiak (2011), a high proportion of lines and pits are characteristics of an abrasive diet. Moreover, the microwear analysis showed the presence of wider scratches, which may be another indicator of an abrasive diet. Scratches and pits are a normal result of the mastication process. To distinguish a more abrasive diet from a less abrasive one, the "width" of the variables must be taken into consideration (Schmidt 2010; Sołtysiak 2011).

Table 2 Shapiro-Wilk test results for the male dataset ( $p *$ non-normal distribution data)

\begin{tabular}{lll}
\hline Variables & $\begin{array}{l}\text { Shapiro- } \\
\text { Wilk }\end{array}$ & $p$ value \\
\hline$s p-l$ & 0.86 & $0.00^{*}$ \\
$s p-w$ & 0.78 & $0.00^{*}$ \\
$l p-l$ & 0.87 & $0.00^{*}$ \\
$l p-w$ & 0.76 & $0.00^{*}$ \\
$f s-l$ & 0.95 & 0.19 \\
$f s-w$ & 0.96 & 0.31 \\
$c s-l$ & 0.93 & $0.03^{*}$ \\
$c s-w$ & 0.96 & 0.27 \\
\hline
\end{tabular}

For a more specific analysis, the data have been divided by sex criteria and have included for each microwear type twodimensional measurements: length and width. In the following analysis, eight variables were included: sp-l (small pitslength), sp-w (small pits-width), lp-1 (large pits-length), lp-w (large pits-width), fs-1 (fine scratches-length), fs-w (fine scratches-width), cs-1 (coarse scratches-length), and cs-w (coarse scratches-width).

\section{Male data analysis}

The data provided from males have shown a non-normal distribution for all variables (Table 2). According to ShapiroWilk test and Q-Q plots, all metric data of the pits and the length of the coarse scratches are non-normally distributed; therefore, nonparametric tests have been applied (MannWhitney U). For the other variables with normal distribution (fs-l, fs-w, cs-w), parametric tests have been used ( $t$ test).

According to Mann-Whitney $U$ test and a $t$ test, no statistically significant differences between the maxillary and mandibular variables were found. The paired sample $t$ test and Wilcoxon test show no statistical differences between the right and left molars, except for the fs-w variable. The fs-w of the left maxillary molar is larger than that of the right $(t$ test $=-$ 3.495; $p=0.01$ ). The descriptive analysis is presented for the entire material in Table 3.

Measurements of the eight variables were included in the PCA analysis. Seven principal components were calculated to account for the total variability in the dataset. The first two represents $54.85 \%$ of the total variability in the sample. The distribution of molars on the first two principal components and the vectors of the variable loading are shown in Fig. 7. Along the first PC, lp-l and cs-l have the greatest contribution to the variability of microwear patterns, and lp-w and s-w less so. As expected, given the results of previous tests, the 
Table 3 Summary statistics for the microwear variables of male data

\begin{tabular}{lllllllll}
\hline & $s p-l$ & $\begin{array}{l}s p- \\
w\end{array}$ & $l p-l$ & $l p-w$ & $f s-l$ & $f s-w$ & $c s-l$ & $\begin{array}{l}c s- \\
w\end{array}$ \\
\hline$N$ & 32 & 32 & 32 & 32 & 32 & 32 & 32 & 32 \\
Minimum & 4.29 & 1.27 & 15.93 & 4.18 & 25.88 & 0.36 & 23.42 & 2.77 \\
Maximum & 9.86 & 7.83 & 42.96 & 22.79 & 136.18 & 1.62 & 203.33 & 7.18 \\
Mean & 6.02 & 3.47 & 23.90 & 9.26 & 75.74 & 0.96 & 84.12 & 5.00 \\
Standard deviation & 1.43 & 1.35 & 7.27 & 4.03 & 27.81 & 0.37 & 38.76 & 0.98 \\
\hline
\end{tabular}

variables embedded in the evaluation of variance models do not reveal particularities in the sample.

\section{Female data analysis}

According to a Shapiro-Wilk test and Q-Q plots, all variables have a normal distribution in the female sample. To compare the data of the maxillary and mandibular second molars, the variables were subjected to the parametric sample $t$ test. No significant differences between measurements were observed. The paired $t$ test reveals differences in microwear patterns of left and right sides based on sp-w, lp-w, fs-w, and cs-w (Table 4). Summary statistics for the variables of both sides are shown in Table 4.
In PCA, the first two principal components account for $55.56 \%$ of the total variability in females. The distribution of molars on the first two principal components and the vectors of the variable loading are shown in Fig. 8. Along the PC, the lp-l and lp-w variables make the greatest contribution, which suggest that the correlation between the length and width has a defining role in the distribution of molars. Apparently, these variables have an important role in the distinction of these two microwear profile models, on the left $\left(\mathrm{M}^{21}, \mathrm{~m}_{21}\right)$ and right $\left(\mathrm{M}^{2 \mathrm{r}}, \mathrm{m}_{2 \mathrm{r}}\right)$ sides. The fs-1 and cs-1 variables have a minimum influence in determining the two patterns.

The presence of the two microwear profiles in females can indicate the existence of a preferred chewing side (PCS) (Pond et al. 1986). Laterality is a relatively common occurrence to variable degrees. In our study, we reduced the factors that
Fig. 7 Scatterplot of the first two principal PCs in male dataset

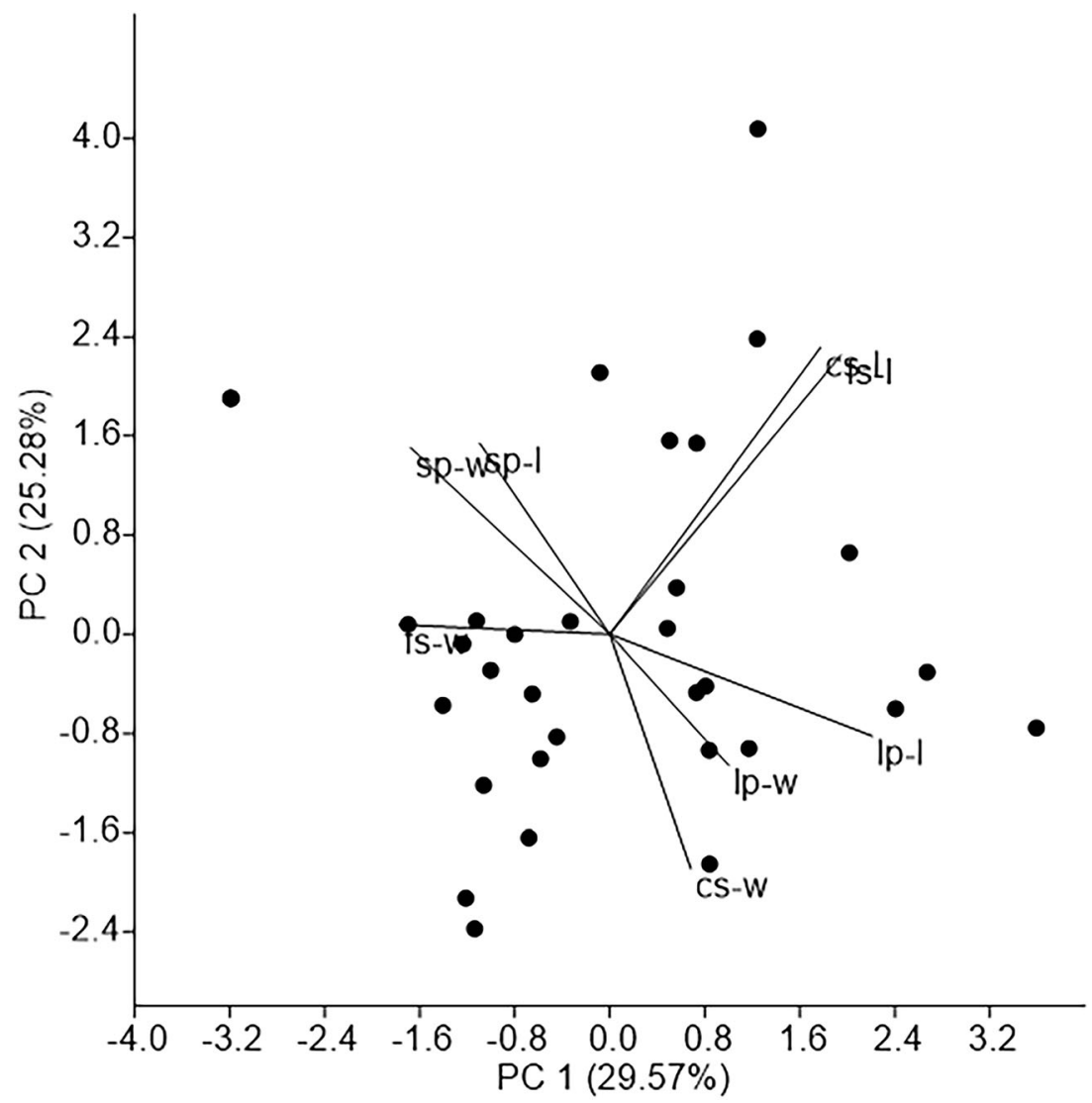


Table 4 Summary statistics for the microwear variables of female data (*statistically significant, $p<0.05$ )

\begin{tabular}{|c|c|c|c|c|c|c|c|c|}
\hline Indices & sp-1 & $\mathrm{sp}-\mathrm{w}^{*}$ & lp-1 & $1 \mathrm{p}-\mathrm{w}^{*}$ & fs-1 & fs-w* & cs-1 & $\begin{array}{l}\text { cs- } \\
\mathrm{W}^{*}\end{array}$ \\
\hline \multicolumn{9}{|l|}{ Right side } \\
\hline$N$ & 12 & 12 & 12 & 12 & 12 & 12 & 12 & 12 \\
\hline Minimum & 3.12 & 1.84 & 15.01 & 5.43 & 55.05 & 0.32 & 56.04 & 4.48 \\
\hline Maximum & 11.06 & 5.41 & 35.42 & 13.55 & 97.68 & 1.86 & 114.76 & 6.15 \\
\hline Mean & 6.30 & 3.45 & 23.26 & 9.43 & 71.84 & 1.32 & 81.52 & 5.14 \\
\hline Standard deviation & 2.18 & 0.96 & 5.76 & 2.26 & 14.13 & 0.45 & 14.98 & 0.46 \\
\hline \multicolumn{9}{|l|}{ Left side } \\
\hline$N$ & 12 & 12 & 12 & 12 & 12 & 12 & 12 & 12 \\
\hline Minimum & 3.79 & 1.50 & 13.21 & 3.75 & 34.59 & 0.32 & 43.47 & 3.40 \\
\hline Махітит & 8.11 & 3.67 & 22.36 & 10.48 & 120.19 & 1.34 & 167.90 & 5.78 \\
\hline Mean & 6.05 & 2.71 & 18.76 & 6.86 & 70.73 & 0.71 & 75.15 & 4.59 \\
\hline Standard deviation & 1.32 & 0.62 & 2.71 & 1.79 & 26.40 & 0.28 & 37.70 & 0.63 \\
\hline \multicolumn{9}{|l|}{ Right vs. left side } \\
\hline t test & 0.2931 & 2.327 & 1.99 & 2.494 & 0.1351 & 3.512 & 0,5497 & 2.192 \\
\hline$p$ value & 0.7749 & 0.04005 & 0.07209 & 0.02983 & 0.8949 & 0.004864 & 0.5935 & 0.050 \\
\hline
\end{tabular}

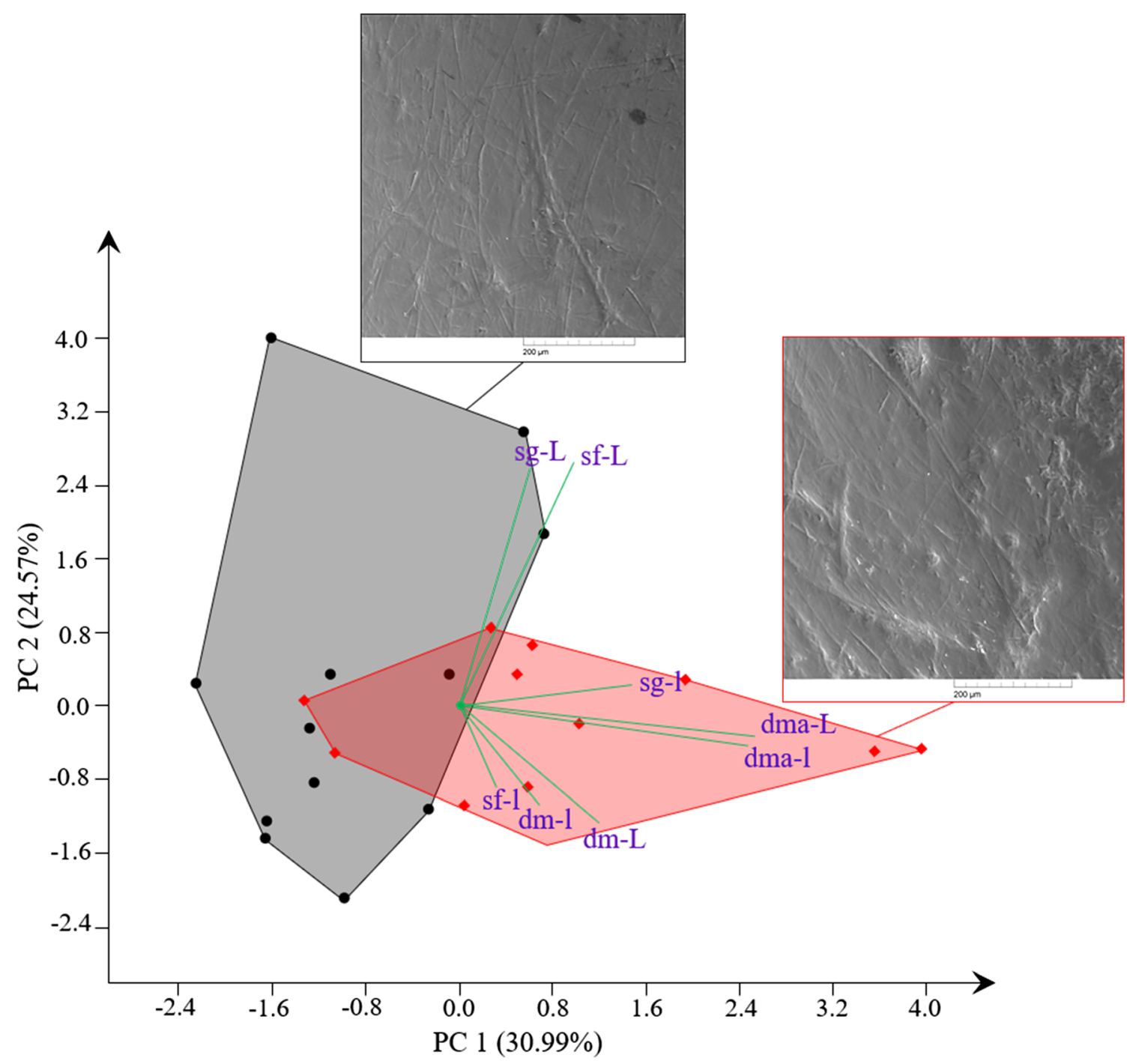

Fig. 8 Scatterplot of the first two principal PCs in female dataset (black, left side; red, right side) (micrograph scale bar=200 $\mu \mathrm{m})$ 
Table 5 CVA loadings

\begin{tabular}{lll}
\hline Variables & Axis 1 & Axis 2 \\
\hline$s p-l$ & -0.16 & 0.40 \\
$s p-w$ & 0.40 & -0.80 \\
$l p-l$ & 0.10 & -0.08 \\
$l p-w$ & 0.00 & -0.07 \\
$f s-l$ & -0.02 & 0.03 \\
$f s-w$ & $\mathbf{2 . 0 4}$ & $\mathbf{2 . 1 9}$ \\
$c s-l$ & 0.02 & -0.02 \\
$c s-w$ & 0.37 & 0.24 \\
\hline
\end{tabular}

might induce laterality as much as possible. Thus, in order to exclude the laterality behavior in people with dental pathologies, we used as a selection criterium for the analyzed teeth the absence of odontopathologies, dental granuloma, or antemortem tooth loss, near and at the studied molars. Research conducted by Mizumori et al. (2003) showed that harder food evoked more laterality. The distribution of food with a hard texture is commonly oriented toward the right side (Zamanlu et al. 2012). Also, we have to mention that our microscopical screening and imaging does not reveal atypical wear types on the occlusal surfaces to suggest the use of teeth as tools.

\section{Comparative analysis}

Given the existence of variation in the female sample, our question is whether there are affinities between female and male patterns. To this end, the eight microwear variables were evaluated through MANOVA and CVA. The results of the multivariate analysis showed a significant difference between microwear patterns (Wilk's Lambda test: Value $=0.536, \mathrm{~F}=$ 2.09, $p<0.01)$.

The CVA loadings resulting from the MANOVA reveal the contribution of variables to the models of microwear patterns in male and female datasets. The variables with loadings higher than 0.3 were considered defining features to clarify affinities between variation patterns (Table 5). A greater affinity in the microwear profiles is highlighted between the male pattern and the right side of female molars (Fig. 9). The fs-w

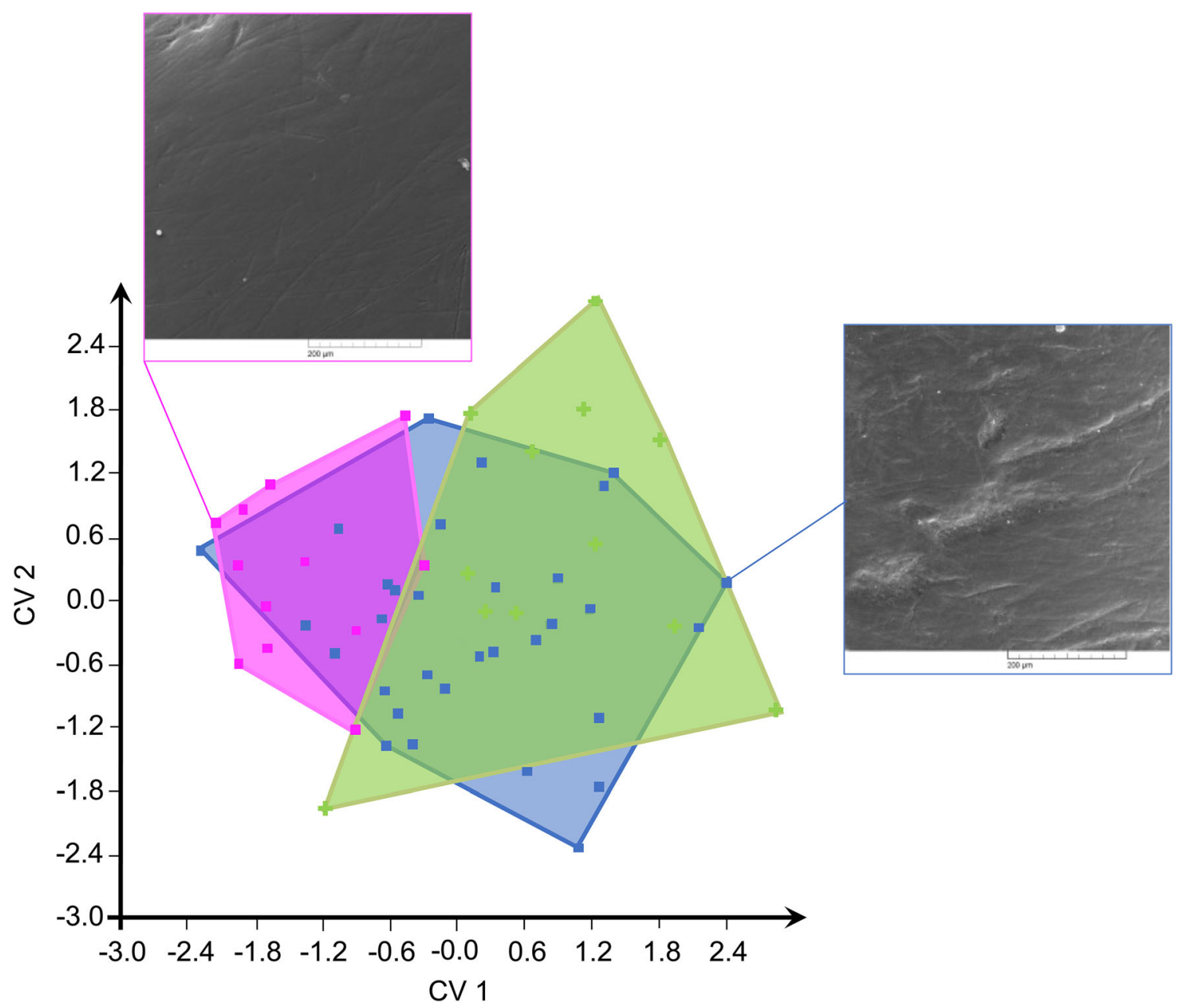

Fig. 9 Plot of CV1 and CV2 (pink, left side females; green, right side females; blue, total males) (micrograph scale bar=200 $\mu \mathrm{m}$ ) 
variable has the highest values in male series, being closer to the values from the right side molars of females (one-way ANOVA: $\mathrm{F}=8.15 ; p=0.00081$; MANOVA: Hotelling's $p$ value 0.05 ).

We hypothesized that men would be characterized by a different microwear profile than women, and the results of our study only partially confirm the initial assumption. The dental microanalysis emphasized a hard and abrasive diet in both males and females, although different microwear profiles were distinguished.

Dietary abrasiveness may be influenced by the number of abrasive particles ingested with food, especially in agriculture products (Romero et al. 2013). Gügel et al. (2001) discovered that different types of cereals can cause varied pit sizes causing a difference in microwear pitting. Also, grit adhering to food can cause microscratches $(0.1-1 \mu \mathrm{m}$ width) comparable to those produced by phytoliths; bones and hard legumes produce a localized microfracture distinguishable from the taphonomic damage (Peters 1982; Ungar et al. 1995). Farmers had a more abrasive diet due to the exogenous grit from the agricultural products in their diets, especially from those with poorly processed foodstuffs (Salazar-García et al. 2016). Grit from unwell processed cereals can be linked to a more abrasive microwear profile (Romero et al. 2013).

Archeological and documentary evidences indicate that the Medieval population in Iasi City used rye, barley, buckwheat, and millet in their diet, cereals that were ground to make flour (Bilavschi 2013). During the major famine in the second half of the seventeenth century, cereals were substituted with dried bulrush which was ground to obtain an alternative kind of flour. The technique of baking bread directly on the clay oven floor increased the content of abrasive particles in the food (Székely 2018).

In males, the microwear profile does not differ by molar laterality, being more homogeneous and characterized predominantly by coarse scratches and pits. Although the archeological research is not finished, we could make the assumption that the male skeletons analyzed may have belonged to guard soldiers in the former "Princely Court," fed with harder and less varied foods.

Our results show two microwear profiles based on molar laterality $\left(\mathrm{M}^{21}, \mathrm{~m}_{21}\right.$ and $\left.\mathrm{M}^{2 \mathrm{r}}, \mathrm{m}_{2 \mathrm{r}}\right)$ in females and one less heterogeneous microwear profile in males. It is well known that, although the human skeleton has a bilateral symmetric development, asymmetry is commonly found in populations (Thiesen et al. 2016). Thus, bilateral disharmonies can be identified in the craniofacial structures, uncorrelated with syndromes, traumas, or pathologies (Primozic et al. 2012). In our study, the microwear pattern associated with the right-sided molars in the female dataset suggests a preferred chewing side used to triturate apart harder foods. Apparently, therefore, a lateralized chewing behavior can affect the dental microwear pattern. In these particular cases, the bias effect can be induced unintentionally and considerably influence the results obtained.

Under these circumstances, we suggest considering the dental wear on both sides (left and right), when the anthropological material exists. Further studies on microwear asymmetry in ancient human populations are required in order to evaluate the frequency and connection between different microwear patterns and a lateralized chewing behavior.

\section{Conclusions}

The occlusal microwear analysis showed a heterogeneous distribution of microwear types on the second molars in each skeleton. The general microwear profile is dominated by linear marks, followed by large pits. We may use the term "abrasive" to characterize the diet of the human population analyzed, due to the high proportion of pronounced traces such as coarse scratches and large pits.

In females, we distinguish two microwear profiles based on the molar laterality. This suggests the use of the right side of the oral cavity to triturate apart harder foods. The microwear profile in males does not differ by laterality, being more homogeneous. It shows close similarity with the pattern of the right second molars in females.

Acknowledgments This project is funded by the Romanian Ministry of Research and Innovation within Program 1 - Development of the national RD system, Subprogram 1.2 - Institutional Performance - RDI excellence funding projects, Contract no.34PFE/19.10.2018.

Open Access This article is licensed under a Creative Commons Attribution 4.0 International License, which permits use, sharing, adaptation, distribution and reproduction in any medium or format, as long as you give appropriate credit to the original author(s) and the source, provide a link to the Creative Commons licence, and indicate if changes were made. The images or other third party material in this article are included in the article's Creative Commons licence, unless indicated otherwise in a credit line to the material. If material is not included in the article's Creative Commons licence and your intended use is not permitted by statutory regulation or exceeds the permitted use, you will need to obtain permission directly from the copyright holder. To view a copy of this licence, visit http://creativecommons.org/licenses/by/4.0/.

\section{References}

Addy M, Shellis R (2006) Interaction between attrition, abrasion and erosion in tooth wear. In: Lussi A (ed) Dental Erosion, From Diagnosis to Therapy. Karger Publishers, Bern, pp 17-31

Badarau D, Caproşu I (2007) Iaşii vechilor zidiri - pina la 1821. Demiurg, Iaşi

Bilavschi G-A (2013) Dinamica economiei agricole din Moldova oglindită în izvoarele veacurilor XIV-XVII. Arheol Mold 36:119-151

Buckley S, Usai D, Jakob T, Radini A, Hardy K (2014) Dental calculus reveals unique insights into food items, cooking and plant processing in prehistoric Central Sudan. PLoS One 9:e100808 
Cloşcă C (2008) Iaşul. Ştef, Iaşi

Cummings LS, Yost C, Sołtysiak A (2018) Plant microfossils in human dental calculus from Nemrik 9, a pre-pottery Neolithic site in northern Iraq. Archaeol Anthropol Sci 10:883-891

Fiorenza L, Benazzi S, Tausch J, Kullmer O, Bromage TG, Schrenk F (2011) Molar macrowear reveals Neanderthal eco-geographic dietary variation. PLoS One 6:e14769

Fiorenza L, Benazzi S, Oxilia G, Kullmer O (2018) Functional relationship between dental macrowear and diet in Late Pleistocene and recent modern human populations. Int J Osteoarchaeol 28:153-161

García-González R, Carretero JM, Richards MP, Rodríguez L, Quam R (2015) Dietary inferences through dental microwear and isotope analyses of the lower Magdalenian individual from El Mirón cave (Cantabria, Spain). J Archaeol Sci 60:28-38

García-González R, Sánchez-Puente Z, Arsuaga JL, Carretero JM (2019) Dietary inferences from dental microwear patterns in chalcolithic populations from the Iberian Peninsula: the case of El Portalón de Cueva Mayor (Sierra de Atapuerca, Burgos, Spain) and El Alto de la Huesera (Álava, Spain). Archaeol Anthropol Sci 11:3811-3823

Górka K, Romero A, Pérez-Pérez A (2016) Dental-macrowear and diet of Tigara foragers from Point Hope, northern Alaska. Anthropol Anz $73: 257-264$

Grine FE (1986) Dental evidence for dietary differences in Australopithecus and Paranthropus: a quantitative analysis of permanent molar microwear. J Hum Evol 15:783-822

Groza V-M (2013) Anthropological research on the urban population inhabiting the city of Iaşi during the medieval period. The 17th century necropolis located on the eastern side of "Curtea Domnească". Memoirs of the Scientific Sections of the Romanian Academy 36:81-96

Groza V-M (2015) Cercetări paleoantropologice privind populația Iașului Medieval. Editura Universității “Alexandru Ioan Cuza” Iași, Iași

Groza V-M, Miu G, Simalcsik A (2011) Data on the demographic structure and longevity of the medieval population of Iasi (the necropolis from the eastern part of the Princely Court, 17th century). In: Cotiugă V, Caliniuc Ș (eds) Interdisciplinarity research in archaeology, proceedings of the first Arheoinvest congress Iași. BAR International Series 2433, pp 123-132

Gügel IL, Grupe G, Kunzelmann KH (2001) Simulation of dental microwear: characteristic traces by opal phytoliths give clues to ancient human dietary behavior. Am J Phys Anthropol 114:124-138

Hammer Ø, Harper DA, Ryan PD (2001) PAST: paleontological statistics software package for education and data analysis. Palaeontol Electron 4:9

Henry AG, Piperno DR (2008) Using plant microfossils from dental calculus to recover human diet: a case study from Tell al-Raqā'i, Syria. J Archaeol Sci 35:1943-1950

Levrini L, Di Benedetto G, Raspanti M (2014) Dental wear: a scanning electron microscope study. Biomed Res Int 2014:7

Mahoney P (2006a) Brief communication: intertooth and intrafacet dental microwear variation in an archaeological sample of modern humans from the Jordan Valley. Am J Phys Anthropol 129:39-44

Mahoney P (2006b) Dental microwear from Natufian hunter- gatherers and early Neolithic farmers: comparisons within and between samples. Am J Phys Anthropol 130:308-319

Michael J, Townsend G, Greenwood L, Kaidonis J (2009) Abfraction: separating fact from fiction. Aust Dent J 54:2-8

Mizumori T, Tsubakimoto T, Iwasaki M, Nakamura T (2003) Masticatory laterality-evaluation and influence of food texture. J Oral Rehabil 30:995-999

Organ JM, Teaford MF, Larsen CS (2005) Dietary inferences from dental occlusal microwear at Mission San Luis de Apalachee. Am J Phys Anthropol 128:801-811

Pérez-Pérez A, Lalueza C, Turbón D (1994) Intraindividual and intragroup variability of buccal tooth striation pattern. Am J Phys Anthropol 94:175-187
Peters CR (1982) Electron-optical microscopic study of incipient dental microdamage from experimental seed and bone crushing. Am J Phys Anthropol 57:283-301

Petraru O-M, Groza V-M, Bejenaru L (2018) Dental macrowear as marker of diet: considerations on the skeletal sample from the 17th century necropolis of Iași (Iași County, Romania). Ann Roum Anthropol 55:45-54

Polo-Cerdá M, Romero A, Casabó J, De Juan J (2007) The bronze age burials from Cova Dels Blaus (Vall d' Uixó, Castelló, Spain): an approach to palaeodietary reconstruction through dental pathology, occlusal wear and buccal microwear patterns. Homo 58:297-307

Pond L, Barghi N, Barnwell G (1986) Occlusion and chewing side preference. J Prosthet Dent 55:498-500

Popovici M, Groza V-M, Petraru O-M, Bejenaru L (2019) Morphometric bioindicators in the typology of human skulls: a sample of 17 th century from Iași city (Romania). Ann Roum Anthropol 56:28-39

Primozic J, Perinetti G, Zhurov A, Richmond S, Ovsenik M (2012) Assessment of facial asymmetry in growing subjects with a threedimensional laser scanning system. Orthod Craniofacial Res 15: 237-244

Razali NM, Wah YB (2011) Power comparisons of Shapiro-Wilk, Kolmogorov-Smirnov, Lilliefors and Anderson-Darling tests. J Stat Modell Anal 2:21-33

Romero A, Ramírez-Rozzi FV, De Juan J, Pérez-Pérez A (2013) Dietrelated buccal dental microwear patterns in Central African Pygmy foragers and Bantu-speaking farmer and pastoralist populations. PLoS One 8:e84804

Salazar-García DC, Romero A, García-Borja P, Subirà ME, Richards MP (2016) A combined dietary approach using isotope and dental buccalmicrowear analysis of human remains from the Neolithic, Roman and Medieval periods from the archaeological site of Tossal de les Basses (Alicante, Spain). J Archaeol Sci Rep 6:610-619

Salazar-García DC, Pérez-Ripoll M, García-Borja P, Pardo JFJ, Tortosa JEA (2017) A terrestrial diet close to the coast: a case study from the Neolithic levels of Nerja cave (Málaga, Spain). In: García-Puchol O, Salazar-García DC (eds) Times of neolithic transition along the Western Mediterranean. Springer: Fundamental Issues in Archaeology, pp 281307

Schmidt CW (2010) On the relationship of dental microwear to dental macrowear. Am J Phys Anthropol 142:67-73

Scott RM, Halcrow SE (2017) Investigating weaning using dental microwear analysis: a review. J Archaeol Sci Rep 11:1-11

Smith AK, Reitsema LJ, Williams FLE, Boano R, Vercellotti G (2019) Sex-and status-based differences in medieval food preparation and consumption: dental microwear analysis at Trino Vercellese. Italy Archaeol Anthropol Sci 11:4789-4800

Soltysiak A (2011) Cereal grinding technology in ancient Mesopotamia: evidence from dental microwear. J Archaeol Sci 38:2805-2810

Strani F, Profico A, Manzi G, Pushkina D, Raia P, Sardella R, DeMiguel D (2018) MicroWeaR: a new R package for dental microwear analysis. Ecol Evol 8:7022-7030

Strani F, DeMiguel D, Alba DM, Moyà-Solà S, Bellucci L, Sardella R, Madurell-Malapeira J (2019) The effects of the " 0.9 Ma event" on the Mediterranean ecosystems during the early-middle Pleistocene transition as revealed by dental wear patterns of fossil ungulates. Quat Sci Rev 210:80-89

Székely MM (2018) Food and Culinary Practices in 17th-Century Moldavia: Tastes, Techniques, Choices. In: Jianu A, Barbu V (eds) Earthly Delights Economies and Cultures of Food in Ottoman and Danubian Europe, c. 1500-1900, vol 23. vol Balkan Studies Library. Brill, pp 170-216

R Core Team (2013) R: a language and environment for statistical computing. Vienna, Austria. http://www.R-project.org/

Thiesen G, Gribel BF, Pereira KCR, Freitas MPM (2016) Is there an association between skeletal asymmetry and tooth absence? Dental Press J Orthod 21:73-79 
Ungar PS (1995) A semiautomated image analysis procedure for the quantification of dental microwear II. Scanning 17:57-59

Ungar PS (2019) Inference of diets of early Hominins from primate molar form and microwear. J Dent Res 98:398-405

Ungar PS, Sponheimer M (2011) The diets of early hominins. Science 334:190-193

Ungar PS, Teaford MF, Glander KE, Pastor RF (1995) Dust accumulation in the canopy: a potential cause of dental microwear in primates. Am J Phys Anthropol 97:93-99

Weyrich LS, Duchene S, Soubrier J, Arriola L, Llamas B, Breen J, Morris AG, Alt KW, Caramelli D, Dresely V, Farrell M, Farrer AG, Francken M, Gully N, Haak W, Hardy K, Harvati K, Held P, Holmes EC, Kaidonis J, Lalueza-Fox C, de la Rasilla M, Rosas A, Semal P, Soltysiak A, Townsend G, Usai D, Wahl J, Huson DH, Dobney K,
Cooper A (2017) Neanderthal behaviour, diet, and disease inferred from ancient DNA in dental calculus. Nature 544:357-361

Xia J, Zheng J, Huang D, Tian ZR, Chen L, Zhou Z, Ungar PS, Qian L (2015) New model to explain tooth wear with implications for microwear formation and diet reconstruction. Proc Natl Acad Sci 112:10669-10672

Zamanlu M, Khamnei S, SalariLak S, Oskoee SS, Shakouri SK, Houshyar Y, Salekzamani Y (2012) Chewing side preference in first and all mastication cycles for hard and soft morsels. Int J Clin Exp Med 5:326

Publisher's note Springer Nature remains neutral with regard to jurisdictional claims in published maps and institutional affiliations. 